\title{
Effectiveness and complications of primary C-clamp stabilization or external fixation for unstable pelvic fractures
}

Hagen Schmal ${ }^{1}$, Morten Schultz Larsen ${ }^{1}$, Fabian Stuby ${ }^{3}$, Peter C. Strohm ${ }^{4}$, Kilian Reising ${ }^{5}$, Kelly Goodwin Burri $^{2}$

${ }^{1}$ Department of Orthopaedics and Traumatology, Odense University Hospital and Department of Clinical Research, University of Southern Denmark, Denmark

${ }^{2}$ Swiss medical Registries and Data Linkage (SwissRDL), Institute of Social and Preventive Medicine (ISPM), University of Bern, Switzerland

${ }^{3}$ BGU Trauma Center Murnau, Murnau, Germany

${ }^{4} \mathrm{Clinic}$ for Orthopaedics and Trauma Surgery, Sozialstiftung Bamberg, Buger Straße 80, 96049 Bamberg, Germany

${ }^{5}$ Department for Orthopaedic Surgery, University Teaching Hospital Harburg, Hamburg, Germany

List of e-mail addresses:

Hagen Schmal: hagen.schmal@rsyd.dk

Morten Schultz Larsen: $\underline{\text { morten.s.larsen@rsyd.dk }}$

Fabian Stuby: fabian.stuby@bgu-murnau.de

Peter C. Strohm: dr.peter.strohm@web.de

Kilian Reising: reisingk@gmx.net

Kelly Goodwin Burri: kelly.goodwin@gmx.ch

Corresponding author:

Hagen Schmal, Professor (ORCID 0000-0002-8801-2385)

Department of Orthopaedics and Traumatology, Odense University Hospital, Odense, Denmark

Sdr. Boulevard 29, 5000 Odense C, e-mail: hagen.schmal@freenet.de

Word count: abstract 249, text 2878

Key words: $\quad$ unstable pelvic fracture - treatment - emergency fixation - registry- logistic regression models - mortality - complication 


\section{HIGHLIGHTS}

1. Initial use of C-clamp or external fixation for unstable pelvic fractures is associated with a decreased mortality.

2. These emergency measures are not an independent risk factor for complications after secondary surgery.

3. The risk for infection after ilio-sacral screw fixation was almost 5-fold increased when primarily a C-clamp was used.

4. In conclusion, emergency stabilization of pelvic fractures is a safe procedure which potentially can save lives.

5. However, the risk for ilio-sacral screw implantation after C-clamp use should be evaluated cautiously. 


\section{Effectiveness and complications of primary C-clamp stabilization or external fixation for unstable pelvic fractures}

Key words: $\quad$ unstable pelvic fracture - treatment - emergency fixation - registry- logistic regression models - mortality-complication 


\section{ABSTRACT}

Background and purpose

Unstable pelvic fractures frequently require emergency stabilization using a C-clamp or external (CC/EF) fixation. However, the effectiveness of this intervention and associated complications are still a matter of debate.

Patients and methods

The analysis used data available from the German Pelvic Trauma Registry to study general complications, infections and mortality after primary stabilization using CC/EF in 5,499 patients ( $n=957$ with vs $n=4,542$ without). Furthermore, the subgroups with secondary surgery ( $n=713$ vs $n=1,695)$, and ilio-sacral screw implantation following C-clamp stabilization were evaluated ( $n=24$ vs $n=219$ ). Calculated odds ratios were adjusted for potential confounders.

Results

Patients treated by CC/EF were younger ( $45 \pm 20$ vs $62 \pm 24$ years), had more C-type fractures (65\% vs $28 \%$ ), higher ISS ( $\geq 2563 \%$ vs $20 \%$ ) and displacement ( $\geq 3 \mathrm{~mm} 81 \%$ vs $41 \%$ ), and more complex fractures $(32 \%$ vs $5 \%)$. These features were independent risk factors for complications $(p<0.001)$. While mortality was reduced after CC/EF stabilization by $32 \%$ (OR $0.6895 \% \mathrm{Cl} 0.49-0.95$ ), the risk for general complications was slightly increased (OR $1.2595 \% \mathrm{Cl}$ 1.02-1.53). In patients undergoing secondary surgery, CC/EF fixation had no influence on mortality, general complications or infections. Related to preceding C-clamp stabilization (OR $4.6795 \% \mathrm{Cl}$ 1.06-20.64), the risk for infection increased from $3.2 \%$ to $20.8 \%$ in ilio-sacral screw fixation.

Interpretation

Primary stabilization of unstable pelvic fractures with C-clamp or external fixation is associated with a decreased mortality and was not an independent risk factor for complications after secondary surgery. However, the risk for infection after ilio-sacral screw fixation increased almost 5-fold after C-clamp use.

\section{INTRODUCTION}

Unstable pelvic fractures often require emergency stabilization using a C-clamp or external fixation [1]. These measures are thought to be effective in stopping haemorrhage, however, they also have potential side effects. While some studies identified independent risk factors for infections in pelvic fractures such as degree of instability [2], embolization [3] or laparotomy [4]; other trials found no association between re-operations and patient's treatment or other injury-associated factors [5]. It is still a matter of debate whether a primary stabilization with C-clamp or external fixation changes the complication pattern or increases the risk of local infections. This is especially interesting and likely because the incisions necessary for both procedures often interfere with later needed surgical approaches.

The purpose of this study was to assess the effectiveness of primary C-clamp stabilization or external fixation for unstable pelvic fractures and associated complications using data from the German Pelvic Trauma Registry. We hypothesized that C-clamp stabilization and external fixation enhance the risk for complications and infections compared with patients without need for these emergency interventions. Concurrently, we expected that the adjusted risk for mortality would be the same in both groups 
because the emergency stabilization should compensate the per se increased instability of patients requiring treatment by C-clamp or external fixation.

\section{METHODS}

This was a cross-sectional study evaluating registry data designed to answer the following research questions:

Q1: How often and in which population are C-clamp stabilization or external fixation used as emergency measures in the treatment of type $B$ and $C$ pelvic fractures?

Q2: Is there a difference between patients who are treated by C-clamp or external fixation or not?

Q3: Is the frequency of general complications, infections and in-hospital death higher in the group treated primarily with external fixation or C-clamp compared with the other patients after correcting for potential confounders?

Q4: Does an emergency stabilization with C-clamp or external fixation increase the complication and infection rate after secondary surgery?

Q5: In the sub-group of patients with implantation of ilio-sacral screws for ilio-sacral or sacral instability, is there a higher infection rate after C-clamp use?

\subsection{Pelvic Trauma Registry Initiative}

Within the Pelvic Trauma Registry Initiative, data from patients with blunt and penetrating pelvic fractures are collected prospectively. The group includes a consortium of trauma departments from 29 university hospitals and level I trauma centres [6-8]. The participating hospitals are required to register all treated cases, which are approved on a yearly basis. Documentation guidelines are supervised by a steering group and communicated during regular meetings twice a year. Data anonymity is guaranteed for the patient and participating hospital. From 2004 (pilot phase from 2001), a secured internet interface hosted by a professional service provider (Swiss medical Registries and Data Linkage, University of Bern, Switzerland) facilitated data management including processing and plausibility checks. Data acquisition and analysis were done in accordance with ethical guidelines and approved by our institutional review board (no. 89/09). The trial was registered at the German Clinical Trials Register (no. 00000488).

\subsection{PATient Selection}

The analysis used data available from the German Pelvic Trauma Registry with an extraction date of 4 November 2016. Patients were eligible for analysis if they had a B- or C- type pelvic fracture treated at a participating center from the time of registry inception until 6 Oct 2016. Unstable fractures involving only the sacrum were excluded because in these cases neither C-clamp nor external fixation were used. All patients meeting the inclusion criteria were included in the analysis.

\subsection{STATISTICAL METHODS}

The outcomes of interest included complications (any general, any infection), and death analyzed as binary variables and registered during the whole hospital stay from admission to discharge. As recently described [9], general complications included thrombosis, embolism, Adult Respiratory Distress Syndrome (ARDS), Multiple Organ Failure (MOF), neurological deficits, bleeding, hematoma, seroma, wound healing problems, implant loosening, implant failure, secondary displacement, and a category "Other". 
All analyses were adjusted for age and gender. Additional variables assessed as risk factors and potential confounders included fracture type (B or C), Injury Severity Score (ISS), maximum displacement (derived as the maximum of all displacement variables in $\mathrm{mm}$ ), laparotomy, embolization, complex fracture, and department case-load of the treating hospital. ISS was treated as a categorical rather than a continuous variable as there are some values that are not possible due to how the score is calculated; categories were based on previous published work [10]. The lowest categories were combined due to low patient numbers with ISS from 4-9. Laparotomy was dichotomized and coded "yes" if a preperitoneal pelvic packing was carried out; missing values were analyzed as "no". Embolization was coded "yes" if angioembolization was carried out as described earlier [11]; missing values changed to "no". Complex fractures were coded for concomitant internal pelvic injuries or open fractures. Department case-load was assessed as categorical variable defined by institutions with $<500,500-999$, or 1000-1500 of the study population enrolled.

The crude odds ratios (OR) and corresponding 95\% confidence intervals (Cls) were calculated for both models. Significance level was set at alpha $=0.05$ for all comparisons.

Bi-variate analysis was used to assess the possible confounding variables by calculating the OR for each outcome adjusted for each potential risk variable individually in turn. Additional variables changing the OR for each outcome by $10 \%$ or greater were considered potential confounders and tested for inclusion in the final multivariable logistic regression model. Age and gender were considered a priori risk factors for all outcomes and included in all regression models.

Two models were used to answer the research questions. Model 1 compared outcomes for patients treated with or without external fixation or C-clamp. Model 2 compared outcomes for the same groups of patients that underwent secondary surgery. ORs and $\mathrm{Cls}$ were calculated in both models for the outcomes general complications, any infections, and death. A subgroup analysis of Model 2 compared the infection rate following IS-screw implantation after C-clamp stabilization or without. Patients with missing data for variables used to determine eligibility or adjustment for confounding $(<10 \%)$ were also excluded from the analysis. All analyses were completed using STATA, version 14 (StataCorp LLC, College Station, TX, USA).

\section{RESULTS}

\subsection{STUDY POPULATION AND BASELINE CHARACTERISTICS}

Between March 2001 and October 2016, 5499 patients met the study inclusion criteria and were included in the analysis (Figure 1). Data records were complete for all variables required for the analysis comparing patients treated with $(n=957,17.4 \%)$ or without C-clamp stabilization or external fixation ( $n=4542,82.6 \%$ ) ("Model 1"). Of the patients treated by one of the emergency measures, 713 had secondary surgery (74.5\%) whereas in the other group 1695 were later operated counting for only $37.3 \%$ ("Model 2").

Baseline characteristics of patients included in Model 1 are presented in Table 1. Overall, patients included had a mean age of $59 \pm 24$ years, with patients treated by emergency stabilization having a mean age approximately 17.5 years younger than those receiving non $(p<0.001)$. Almost $60 \%$ of the patients were female, but a higher proportion of men needed pelvic clamp or external fixation (64.7\%) compared with the group without (36.3\%). There were 3626 (65.9\%) of patients with B-type fracture and 1873 (34.1\%) with C-type fractures included. Patients treated with stabilizing emergency measures had also a higher chance to undergo emergency measures to stop active haemorrhage such as a laparotomy for pelvic packing and selective embolization $(p<0.001)$. Furthermore, they were generally more likely to have higher ISS (injury severity score), and larger maximum displacement $(p<0.001)$. The 
higher the case-load of a hospital the higher was the chance that patients were stabilized with C-clamp (CC) or external fixation (EF).

Baseline characteristics of patients with and without CC or EF undergoing later surgery are presented in Table 2 (Model 2). Principally, the pattern for this subgroup was the same as seen for all patients. Additionally, the portion of patients being treated by ilio-sacral screw stabilization was analysed in both groups reaching $12.9 \%$ and $14.7 \%$, respectively, which was not statistically significantly different.

\subsection{EXternal FiXATION OR C-CLAMp (MOdel 1)}

Results for model 1 are presented as crude and adjusted ORs for each outcome (general and infectious complications, death) in Table 3. Results from bi-variate analyses indicated that year of surgery and hospital case-load were not associated with any of the outcomes analysed and were not included in the multivariable model. When no odds are reported, the case load was too small for statistically meaningful conclusions.

\subsubsection{General complications}

Of the 847 (15.4\%) patients overall that experienced complications, the proportion in the group that had received a form of emergency stabilization ( $n=273,28.5 \%$ ) was larger than in those treated without ( $n=574,12.6 \%, p<0.001$ ). After adjusting for confounding factors, the odds of general complications was 1.25 times higher for patients initially stabilized with C-clamp or external fixation than those without (OR=1.25, 95\% $\mathrm{Cl}$ 1.02-1.53). The odds of general complications was increased in men and complex or vertically unstable type $C$ fractures, elevated with increasing age, ISS, and a maximum displacement $>2 \mathrm{~mm}$ (Table 3).

\subsubsection{Infections}

Less than $3 \%$ of all patients analysed experienced an infection ( $n=143,2.6 \%)$. Of those patients, a higher proportion of patients receiving a form of emergency stabilization ( $n=52,5.4 \%$ ) experienced infections than those treated without $(2.0 \%, p<0.001)$, with the crude odds of infection 2.8 times higher for those with an emergency stabilization (Table 3). However, after adjusting for confounding factors, the odds of infections was not higher for patients initially stabilized with C-clamp or external fixation than those without $(\mathrm{OR}=1.28,95 \% \mathrm{Cl} 0.86-1.92)$. The odds of infections was elevated with increasing ISS, in complex, and type $\mathrm{C}$ fractures (Table 3 ).

\subsubsection{Death}

There were 306 (5.6\%) deaths reported overall, with 102 (10.7\%) deaths in the group treated with Cclamp (CC) or external fixation (EF) compared with 204 (4.5\%) in the group without emergency stabilization. Although the crude odds indicated a higher chance to die after CC/EF treatment, the adjusted odds for risk of death was actually $32 \%$ lower in the CC/EF group (OR=0.68, 95\% Cl 0.49-0.95). This was caused by the different distribution of the other risk factors. The odds of death increased specifically with increasing age and ISS (Table 3 ).

\subsection{SeCOndary SuRgery (MOdel2)}

Results for model 2 are presented as crude and adjusted ORs for each outcome in Table 4. Results from bi-variate analyses indicated that year of surgery and hospital case-load were not associated with any of the outcomes analysed and were not included in the multivariablemodel. 


\subsubsection{General complications, infections, death}

Crude OR indicate that patients treated by CC/EF in the first place have a higher risk to sustain general complications, infections and to die. However, adjusted ORs showed no difference. Unevenly distributed but relevant risk factors for general complications were high age, ISS, displacement and the presence of complex fractures, C-type injuries, and laparotomy. This was similar in patients with infection, however, high displacement and ISS were not separate risk factors. Odds indicated the influence of high age, ISS, displacement and the presence of C-type injuries, and laparotomy on mortality.

\subsubsection{Subgroup analysis - ilio-sacral screws}

This subgroup analysis aimed to investigate the infection rate after stabilization of the pelvis using iliosacral screws comparing patients that were primarily treated with C-clamp with a group without this emergency measure. The relative frequency of infections was higher in the patients being treated by C-clamp (20.8\% vs $3.2 \%$, Table 5$)$. Caused by the low total amount of cases, the calculation of the adjusted ORs was limited (Table 6). However, based on the available data, the adjusted OR was also higher for this group $(\mathrm{OR}=4.67,95 \% \mathrm{Cl} 1.06-20.64)$, indicating the increased risk of infection in this subgroup.

\section{DISCUSSION}

Patients treated with C-clamp or external fixation were younger, had more C-type fractures, a higher ISS and fracture displacement, more other emergency measures such as pelvic packing and embolization, and more complex fractures (internal organs involved). Since all these factors -the Injury Severity Score (ISS) being the most important one - influence the analyzed outcome measures such as general complications, infections and mortality, the adjusted odds were calculated to evaluate the emergency stabilization as an independent risk factor. By this, it could be shown that mortality was reduced in the group being stabilized with C-clamp or external fixation by $32 \%$, while the risk to suffer from general complications was slightly increased (25\%). In the subgroup of secondary surgery, Cclamp or external fixation had no influence on mortality and the risks for complications including infection. However, in the subgroup of ilio-sacral screw fixation following C-clamp use, the risk of infection increased from 3.2 to $20.8 \%$, which partially could be attributed to emergency fixation.

The current literature leaves no doubt that patients in need for any emergency stabilization have a higher risk to die and to suffer from all kinds of complications [12]. However, until now it has not been analyzed whether the emergency treatment itself is effective and/or an independent risk factor for complications. Considering that current guidelines for treatment of hemodynamically unstable pelvic fractures recommend use of pelvic clamp and external fixation $[13,14]$, the need for a clarification of this issue becomes obvious - also regarding a risk-benefit evaluation. Our data confirm recent studies [7] and show an absolute increase in mortality, infection- and complication rate in this population by 2.5-2.8 (crude odds). In contrast to our hypothesis that mortality is leveled out in the groups being treated or not treated by pelvic clamp and/or external fixation, our data for the adjusted odds indicate that mortality is even decreased by $32 \%$, which could directly be attributed to these measures. This confirms the efficacy of these procedures and emphasizes that biomechanical stabilization should be an integral part of the emergency management of unstable pelvic fractures [15].

A look at the subgroup of later operated patients could partially explain this very positive effect. While the crude odds again demonstrated a higher risk for all outcome parameters, after adjusting for confounding factors the results showed no effect at all. This indicates that in the first group the increased mortality of patients without emergency stabilization may be attributed to those who came in such bad conditions to the emergency room that it was decided to stop resuscitation immediately. 
The second group describes patients who survived the first peak of death [16]. However, the results emphasize again that there is no increased general risk associated with the pure application of C-clamp or external fixation. Although there are specific complications described after use of C-clamp [17] or external fixation [18], the conclusion can be drawn that on average the complication rate is not higher after emergency stabilization. The clinical consequence of these findings is that, when in doubt, patients should be stabilized because C-clamp and external fixation have a good, life-saving effect and do not harm.

However, there is one exception. Referring to our results analyzing the combination of C-clamp with later ilio-sacral screw implantation, an almost 5 -fold increased risk for infection (adjusted odds) needs to be assumed. Considering the low case numbers in this subgroup, it apparently does not affect the results of the analysis of the entire population. Nevertheless, the treating surgeon needs to be aware of this constellation and possibly avoid the combination of pelvic clamp and consecutive ilio-sacral screws whenever possible. Therefore, a general recommendation cannot entirely replace the individual evaluation of the specific situation. It is generally approved that the application of C-clamp or external fixation needs training [19]. All participating centers have experience with treatment of pelvic fractures, and therefore, a certain level of education for the teams in the emergency room is ensured. Nonetheless, our data revealed that patients being acutely stabilized were more likely treated at hospitals with a higher case load. Although this indicates that the more severe cases were treated at larger hospitals, the case load among experienced centers had no influence on any of the examined outcome parameters.

The usual bleeding sources in unstable pelvic fractures comprise the cancellous bone of the fracture sites, the venous plexus of the pelvis, closed or open soft tissue damage and branches of the internal iliac artery. Therefore, it was expected that biomechanical stabilization was very often combined with pelvic packing or selective embolization, which has shown to decrease mortality [20]. In the whole population and the subgroup of later operatively treated patients, pelvic packing (laparotomy) was an independent risk factor for death, which is in line with recently published data [11,21]. Although the procedure has shown to be effective [22], patients with necessity for this procedure had an overall increased risk to die compared to all pelvic fractures.

This analysis has several limitations which are associated with the study design, an evaluation of a single registry. Therefore, some relevant data regarding co-morbidity including Body Mass Index [23], life style or socioeconomic status were not entered, which might potentially bias the complication rate and mortality. Partially, this could be leveled out by correcting for age and gender. Unfortunately, the study lacks long-term data and patient-related outcome measures, which are associated with complications in the course of treatment [24].

\section{CONCLUSION}

Finally, it may be concluded that initial stabilization of unstable pelvic fractures with C-clamp or external fixation might decrease mortality and is not an independent risk factor for complications after secondary surgery. Only the generally low risk for infection after ilio-sacral screw fixation was increased almost 5-fold after C-clamp use. This means for clinical decision-making that patients should in doubt be stabilized, and the risk for ilio-sacral screw implantation after C-clamp use should be evaluated cautiously. 


\section{LEGEND}

Figure 1: Patient flow chart

Table 1: Baseline characteristics of patients with and without C-clamp stabilization (CC) or external fixation (EF) (Model 1)

Table 2. Baseline characteristics of patients with and without C-clamp stabilization (CC) or external fixation (EF) undergoing surgery (Model 2)

Table 3: Crude and adjusted odds ratios for effect of C-clamp or external fixation for outcomes complications, infection, and death (Model 1)

Table 4: Crude and adjusted odds ratios for effect of C-clamp or external fixation in patients with secondary surgery for outcomes complications, infection, and death (Model 2)

Table 5: Comparison of infections among patients undergoing secondary surgery with IS screws with and without C-clamp (Model 2 subgroup analysis)

Table 6: Crude and adjusted OR for infections among patients undergoing secondary surgery with IS screws with and without C-clamp (Model 2 subgroup analysis)

\section{REFERENCES}

[1] Pizanis A, Pohlemann T, Burkhardt M, Aghayev E, Holstein JH. Emergency stabilization of the pelvic ring: Clinical comparison between three different techniques. Injury 2013;44:1760-4. doi:10.1016/j.injury.2013.07.009.

[2] Stover MD, Sims S, Matta J. What is the infection rate of the posterior approach to type $C$ pelvic injuries? Clin Orthop 2012;470:2142-7. doi:10.1007/s11999-012-2438-9.

[3] Matityahu A, Marmor M, Elson JK, Lieber C, Rogalski G, Lin C, et al. Acute complications of patients with pelvic fractures after pelvic angiographic embolization. Clin Orthop 2013;471:2906-11. doi:10.1007/s11999-013-3119-z.

[4] Miskimins R, Decker M, Hobby B, Howdieshell T, Lu S, West SD. Complications of pelvic ring fixation in patients requiring laparotomy. J Surg Res 2015;199:244-8. doi:10.1016/j.jss.2015.05.051.

[5] Ochenjele G, Reid KR, Castillo RC, Schoonover CD, Montalvo RN, Manson TT, et al. Predictors of Unplanned Reoperation after Operative Treatment of Pelvic Ring Injuries. J Orthop Trauma 2018. doi:10.1097/BOT.0000000000001170.

[6] Hauschild O, Strohm PC, Culemann U, Pohlemann T, Suedkamp NP, Koestler W, et al. Mortality in patients with pelvic fractures: results from the German pelvic injury register. J Trauma 2008;64:449-55. doi:10.1097/TA.0b013e31815982b1.

[7] Pohlemann T, Stengel D, Tosounidis G, Reilmann H, Stuby F, Stöckle U, et al. Survival trends and predictors of mortality in severe pelvic trauma: estimates from the German Pelvic Trauma Registry Initiative. Injury 2011;42:997-1002. doi:10.1016/j.injury.2011.03.053.

[8] Zwingmann J, Aghayev E, Südkamp NP, Neumann M, Bode G, Stuby F, et al. Pelvic Fractures in Children Results from the German Pelvic Trauma Registry: A Cohort Study. Medicine (Baltimore) 2015;94:e2325. doi:10.1097/MD.0000000000002325.

[9] Schmal H, Froberg L, S Larsen M, Südkamp NP, Pohlemann T, Aghayev E, et al. Evaluation of strategies for the treatment of type B and C pelvic fractures. Bone Jt J 2018;100-B:973-83. doi:10.1302/0301-620X.100B7.BJJ-2017-1377.R1.

[10] Stevenson M, Segui-Gomez M, Lescohier I, Di Scala C, McDonald-Smith G. An overview of the injury severity score and the new injury severity score. Inj Prev J Int Soc Child Adolesc Inj Prev 2001;7:10-3. 
[11] Hauschild O, Aghayev E, von Heyden J, Strohm PC, Culemann U, Pohlemann T, et al. Angioembolization for pelvic hemorrhage control: results from the German pelvic injury register. J Trauma Acute Care Surg 2012;73:679-84. doi:10.1097/TA.0b013e318253b5ba.

[12] Esmer E, Esmer E, Derst P, Schulz M, Siekmann H, Delank KS, et al. [Influence of external pelvic stabilization on hemodynamically unstable pelvic fractures]. Unfallchirurg 2017;120:312-9. doi:10.1007/s00113-015-0119-3.

[13] Marzi I, Lustenberger T. Management of Bleeding Pelvic Fractures. Scand J Surg SJS Off Organ Finn Surg Soc Scand Surg Soc 2014;103:104-11. doi:10.1177/1457496914525604.

[14] Tran TLN, Brasel KJ, Karmy-Jones R, Rowell S, Schreiber MA, Shatz DV, et al. Western Trauma Association Critical Decisions in Trauma: Management of pelvic fracture with hemodynamic instability-2016 updates. J Trauma Acute Care Surg 2016;81:1171-4. doi:10.1097/TA.0000000000001230.

[15] Metcalfe AJ, Davies K, Ramesh B, O'Kelly A, Rajagopal R. Haemorrhage control in pelvic fractures-a survey of surgical capabilities. Injury 2011;42:1008-11. doi:10.1016/j.injury.2010.11.062.

[16] Vaidya R, Scott AN, Tonnos F, Hudson I, Martin AJ, Sethi A. Patients with pelvic fractures from blunt trauma. What is the cause of mortality and when? Am J Surg 2016;211:495-500. doi:10.1016/j.amjsurg.2015.08.038.

[17] Kim W-Y, Lee S-W, Kim K-S, Lee J-Y. Superior Gluteal Artery Pseudoaneurysm Caused by Pelvic CClamp Blind Application: A Case Report. Hip Pelvis 2017;29:145-9. doi:10.5371/hp.2017.29.2.145.

[18] McDonald C, Firoozabadi R, Routt ML, Kleweno C. Complications Associated With Pelvic External Fixation. Orthopedics 2017;40:e959-63.doi:10.3928/01477447-20170918-02.

[19] Koller H, Keil P, Seibert F. Individual and team training with first time users of the Pelvic C-Clamp: do they remember or will we need refresher trainings? Arch Orthop Trauma Surg 2013;133:3439. doi:10.1007/s00402-012-1664-7.

[20] Burlew CC, Moore EE, Stahel PF, Geddes AE, Wagenaar AE, Pieracci FM, et al. Preperitoneal pelvic packing reduces mortality in patients with life-threatening hemorrhage due to unstable pelvic fractures. J Trauma Acute Care Surg 2017;82:233-42. doi:10.1097/TA.0000000000001324.

[21] Schmal H, Markmiller M, Mehlhorn AT, Sudkamp NP. Epidemiology and outcome of complex pelvic injury. Acta Orthop Belg 2005;71:41-7.

[22] Magnone S, Allievi N, Ceresoli M, Coccolini F, Pisano M, Ansaloni L. Prospective validation of a new protocol with preperitoneal pelvic packing as the mainstay for the treatment of hemodynamically unstable pelvic trauma: a 5-year experience. Eur J Trauma Emerg Surg Off Publ Eur Trauma Soc 2019. doi:10.1007/s00068-019-01115-3.

[23] Carson JT, Shah SG, Ortega G, Thamyongkit S, Hasenboehler EA, Shafiq B. Complications of pelvic and acetabular fractures in 1331 morbidly obese patients (BMI $\geq 40$ ): a retrospective observational study from the National Trauma Data Bank. Patient Saf Surg 2018;12:26. doi:10.1186/s13037-018-0172-2.

[24] Brenneman FD, Katyal D, Boulanger BR, Tile M, Redelmeier DA. Long-term outcomes in open pelvic fractures. J Trauma 1997;42:773-7.

\section{SUPPLEMENTARY INFORMATION}

\subsection{AVAILABILITY OF DATA AND MATERIAL}

The data generated and analyzed during this study are available from the corresponding author on reasonable request. 


\subsection{COMPETING INTERESTS}

The authors declare that they have no conflict of interest.

\subsection{FUNDING}

There is no funding source.

\subsection{ETHICAL APPROVAL}

Data acquisition and analysis were done in accordance with ethical guidelines and approved by our institutional review board (no. 89/09). The trial was registered at the German Clinical Trials Register (no. 00000488). 


\section{ACKNOWLEDGEMENTS}

None.

\section{AUTHORS' CONTRIBUTIONS}

HS was responsible for conception and design, analysis and interpretation of data, wrote the manuscript and submitted the final version.

MSL made substantial contributions to interpretation of data; manuscript preparation and gave final approval for the version to be published.

FS supported the conception of the study and data extraction from the registry, contributed to the interpretation of the data, and approved the submitted article.

PCS was involved in the conception of the study, supported the interpretation of the data, and approved the submitted article.

KGB carried out the statistical analysis, substantially contributed to the manuscript especially regarding methods and results, was involved in the conception of the study, critically revised the article draft, and approved the final version. 


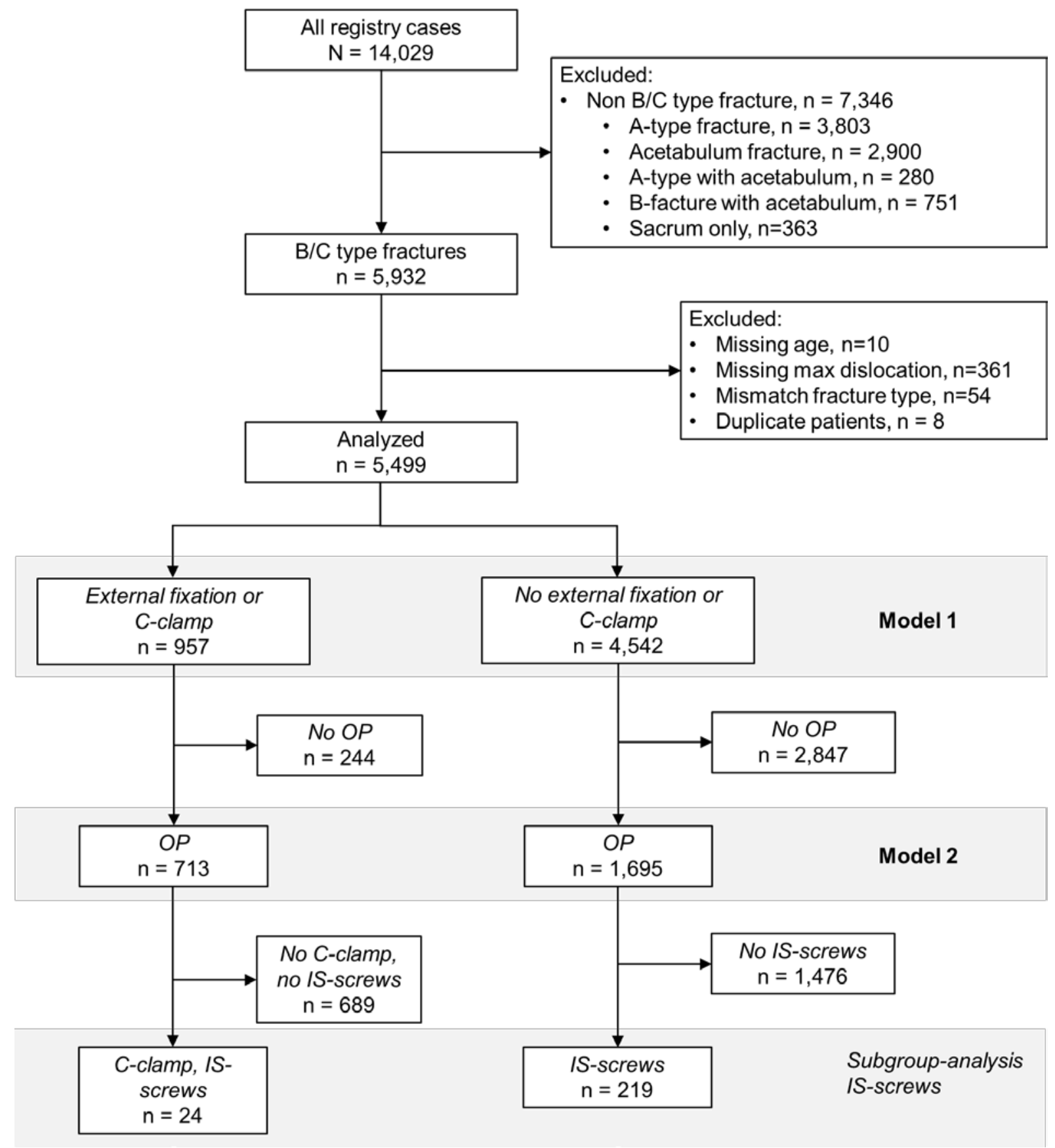

Figure 1: Patient flow chart 
Table 1. Baseline characteristics of patients with and without C-clamp stabilization (CC) or external fixation (EF) (Model 1)

\begin{tabular}{|c|c|c|c|c|c|c|c|}
\hline & \multicolumn{2}{|c|}{$\begin{array}{l}\text { No CC/EF } \\
N=4,542\end{array}$} & \multicolumn{2}{|c|}{$\begin{array}{c}\text { With CC/EF } \\
N=957\end{array}$} & \multicolumn{2}{|c|}{$\begin{array}{c}\text { Total } \\
N=5,499\end{array}$} & \multirow[t]{2}{*}{ p-value* } \\
\hline & $\mathrm{n}$ & $\%$ & $\mathrm{n}$ & $\%$ & $\mathrm{n}$ & $\%$ & \\
\hline \multicolumn{8}{|l|}{ Age (years) } \\
\hline Mean (SD) & 62.0 & $(23.8)$ & 44.5 & (19.9) & 59.0 & (24.1) & $<0.001$ \\
\hline$<20$ & 270 & 5.9 & 111 & 11.6 & 381 & 6.9 & $<0.001$ \\
\hline $20-39$ & 723 & 15.9 & 291 & 30.4 & 1,014 & 18.4 & \\
\hline $40-59$ & 876 & 19.3 & 341 & 35.6 & 1,217 & 22.1 & \\
\hline $60-79$ & 1,301 & 28.6 & 168 & 17.6 & 1,469 & 26.7 & \\
\hline $80+$ & 1,372 & 30.2 & 46 & 4.8 & 1,418 & 25.8 & \\
\hline \multicolumn{8}{|l|}{ Gender } \\
\hline male & 1,647 & 36.3 & 619 & 64.7 & 2,266 & 41.2 & $<0.001$ \\
\hline female & 2,895 & 63.7 & 338 & 35.3 & 3,233 & 58.8 & \\
\hline \multicolumn{8}{|l|}{ Fracture type } \\
\hline B & 3,286 & 72.4 & 340 & 35.5 & 3,626 & 65.9 & $<0.001$ \\
\hline C & 1,256 & 27.7 & 617 & 64.5 & 1,873 & 34.1 & \\
\hline \multicolumn{8}{|l|}{ ISS (total score) } \\
\hline 4-14 & 2,584 & 56.9 & 109 & 11.4 & 2,693 & 49.0 & $<0.001$ \\
\hline $16-24$ & 1,070 & 23.6 & 246 & 25.7 & 1,316 & 23.9 & \\
\hline$\geq 25$ & 888 & 19.6 & 602 & 62.9 & 1,490 & 27.1 & \\
\hline \multicolumn{8}{|l|}{ Laparotomy } \\
\hline No & 4,512 & 99.3 & 802 & 83.8 & 5,314 & 96.6 & $<0.001$ \\
\hline Yes & 30 & 0.7 & 155 & 16.2 & 185 & 3.4 & \\
\hline \multicolumn{8}{|l|}{ Embolization } \\
\hline No & 4,534 & 30.0 & 916 & 95.7 & 5,450 & 99.1 & $<0.001$ \\
\hline Yes & 8 & 0.7 & 41 & 4.3 & 49 & 0.9 & \\
\hline \multicolumn{8}{|c|}{ Complex fracture } \\
\hline No & 4,312 & 94.9 & 658 & 68.8 & 4,970 & 90.4 & $<0.001$ \\
\hline Yes & 230 & 5.1 & 299 & 31.2 & 529 & 9.6 & \\
\hline \multicolumn{8}{|c|}{ Maximum displacement (mm) } \\
\hline Mean (SD) & 3.4 & $(5.1)$ & 8.4 & $(7.8)$ & 4.3 & $(6.0)$ & $<0.001$ \\
\hline$<2 \mathrm{~mm}$ & 1,614 & 35.5 & 89 & 9.3 & 1,703 & 31.0 & $<0.001$ \\
\hline $2 \mathrm{~mm}$ & 1,071 & 23.6 & 95 & 9.9 & 1,166 & 21.2 & \\
\hline$\geq 3 \mathrm{~mm}$ & 1,857 & 40.9 & 773 & 80.8 & 2,630 & 47.8 & \\
\hline \multicolumn{8}{|c|}{ Hospital no. cases } \\
\hline$<500$ & 947 & 20.9 & 210 & 21.9 & 1,157 & 21.0 & $<0.001$ \\
\hline $500-999$ & 1,844 & 40.6 & 286 & 29.9 & 2,130 & 38.7 & \\
\hline $1000-1500$ & 1,751 & 38.6 & 461 & 48.2 & 2,212 & 40.2 & \\
\hline
\end{tabular}

Values are $n, \%$ unless otherwise specified.

* $\mathrm{p}$-value for chi-squared test for categorical values, t-test for mean of continuous variables 
Table 2. Baseline characteristics of patients with and without C-clamp stabilization (CC) or external fixation (EF) undergoing surgery (Model 2)

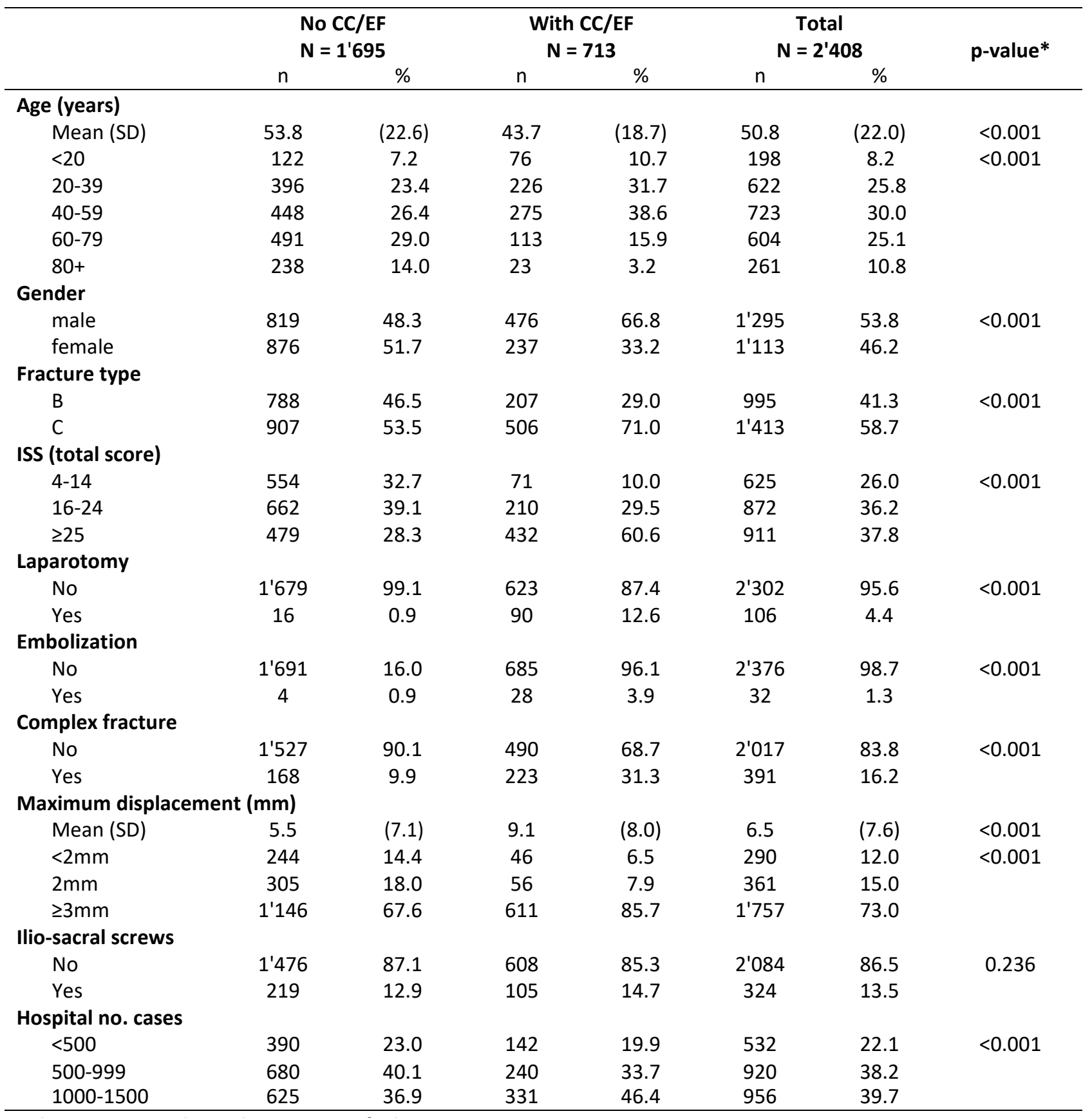

Values are $n, \%$ unless otherwise specified.

*p-value for chi-squared test for categorical values, t-test for mean of continuous variables 
Accepted author's manuscript. Injury. Publisher DOI: https://doi.org/10.1016/i.injury.2019.08.039

Table 1. Crude and adjusted odds ratios for effect of C-clamp or external fixation for outcomes complications, infection, and death (model 1)

\begin{tabular}{|c|c|c|c|c|c|c|}
\hline \multirow[b]{2}{*}{ Adjustment } & \multicolumn{2}{|c|}{ General Complications } & \multicolumn{2}{|c|}{ Infection } & \multicolumn{2}{|l|}{ Death } \\
\hline & OR $(95 \% \mathrm{Cl})$ & p-value & OR $(95 \% \mathrm{Cl})$ & p-value & OR $(95 \% \mathrm{Cl})$ & p-value \\
\hline \multicolumn{7}{|l|}{ Crude } \\
\hline With C-clamp/ext. fixation & $2.76(2.34-3.26)$ & $<0.001$ & $2.81(1.98-3.98)$ & $<0.001$ & $2.54(1.98-3.25)$ & $<0.001$ \\
\hline \multicolumn{7}{|l|}{ Adjusted } \\
\hline No C-clamp/ext. fixation & ref & 0.032 & ref & 0.229 & ref & 0.023 \\
\hline \multicolumn{7}{|l|}{ Sex } \\
\hline Male & ref & 0.036 & ref & 0.362 & ref & 0.494 \\
\hline Female & $0.83(0.70-0.99)$ & & $0.85(0.59-1.21)$ & & $1.10(0.84-1.44)$ & \\
\hline Age (years) & $1.02(1.01-1.02)$ & $<0.001$ & $1.01(1.00-1.02)$ & 0.063 & $1.03(1.03-1.04)$ & $<0.001$ \\
\hline \multicolumn{7}{|l|}{ ISS (total score) } \\
\hline \multicolumn{7}{|l|}{ Complex fracture } \\
\hline No & ref & $<0.001$ & ref & 0.001 & ref & 0.090 \\
\hline Yes & $2.62(2.10-3.28)$ & & $2.07(1.34-3.20)$ & & $1.35(0.96-1.91)$ & \\
\hline \multicolumn{7}{|l|}{ Fracture type } \\
\hline B & ref & $<0.001$ & ref & 0.001 & - & - \\
\hline $\mathrm{C}$ & $1.49(1.22-1.83)$ & & $2.06(1.3-3.26)$ & & - & \\
\hline \multicolumn{7}{|l|}{ Maximum displacement } \\
\hline$<2 \mathrm{~mm}$ & ref & $<0.001$ & ref & 0.081 & - & - \\
\hline $2 \mathrm{~mm}$ & $1.29(0.99-1.68)$ & & $1.42(0.74-2.75)$ & & - & \\
\hline$\geq 3 \mathrm{~mm}$ & $1.86(1.48-2.34)$ & & $1.85(1.05-3.27)$ & & - & \\
\hline
\end{tabular}


Accepted author's manuscript. Injury. Publisher DOI: https://doi.org/10.1016/i.injury.2019.08.039

Table 4. Crude and adjusted odds ratios for effect of C-clamp or external fixation in patients with secondary surgery for outcomes complications, infection, and death (model 2)

\begin{tabular}{|c|c|c|c|c|c|c|}
\hline \multirow[b]{2}{*}{ Adjustment } & \multicolumn{2}{|c|}{ General Complications } & \multicolumn{2}{|c|}{ Infection } & \multicolumn{2}{|l|}{ Death } \\
\hline & OR $(95 \% \mathrm{Cl})$ & p-value & OR $(95 \% \mathrm{Cl})$ & p-value & OR $(95 \% \mathrm{Cl})$ & p-value \\
\hline \multicolumn{7}{|l|}{ Crude } \\
\hline With C-clamp/ext. fixation & $1.61(1.31$ - 1.97) & $<0.001$ & $1.46(1.01-2.12)$ & 0.046 & $1.75(1.03-2.99)$ & 0.039 \\
\hline \multicolumn{7}{|l|}{ Adjusted } \\
\hline No C-clamp/ext. fixation & ref & 0.179 & ref & 0.791 & ref & 0.123 \\
\hline \multicolumn{7}{|l|}{ Sex } \\
\hline Male & ref & 0.549 & ref & 0.788 & ref & 0.558 \\
\hline Female & $0.94(0.76-1.16)$ & & $0.95(0.65-1.39)$ & & $0.83(0.45-1.53)$ & \\
\hline Age (years) & $1.02(1.02-1.03)$ & $<0.001$ & $1.01(1.00-1.02)$ & 0.010 & $1.07(1.05-1.08)$ & $<0.001$ \\
\hline \multicolumn{7}{|l|}{ ISS total score } \\
\hline \multicolumn{7}{|l|}{ Complex fracture } \\
\hline No & ref & $<0.001$ & ref & 0.009 & ref & 0.150 \\
\hline Yes & $2.17(1.65-2.84)$ & & $1.92(1.2-3.08)$ & & $1.71(0.83-3.51)$ & \\
\hline \multicolumn{7}{|l|}{ Fracture type } \\
\hline B & ref & 0.004 & ref & 0.042 & ref & 0.020 \\
\hline $\mathrm{C}$ & $1.45(1.12-1.88)$ & & $1.63(1.00-2.66)$ & & $0.47(0.25-0.88)$ & \\
\hline \multicolumn{7}{|l|}{ Maximum dislocation } \\
\hline$<2 \mathrm{~mm}$ & ref & 0.010 & - & - & - & - \\
\hline $2 \mathrm{~mm}$ & $0.75(0.48-1.16)$ & & - & & - & \\
\hline$\geq 3 \mathrm{~mm}$ & $1.21(0.86-1.71)$ & & - & & - & \\
\hline
\end{tabular}

P-value for multi-variate model based on likelihood ratio test. Maximum dislocation was not a confounding factor for infection or death and was excluded from the final models for these outcomes (ref-reference). 
Accepted author's manuscript. Injury. Publisher DOI: https://doi.org/10.1016/i.injury.2019.08.039

Table 5. Comparison of infections among patients undergoing secondary surgery with IS screws with and without C-clamp (Model 2 subgroup analysis)

\begin{tabular}{lcc}
\hline Exposure & Infection & No infection \\
\hline IS screws and C-clamp & $\mathbf{n}(\%)$ & $\mathbf{n}(\%)$ \\
IS screws, no C-clamp & $5(20.8)$ & $19(79.2)$ \\
Total & $7(3.2)$ & $212(96.8)$ \\
\hline
\end{tabular}


Table 6. Crude and adjusted OR for infections among patients undergoing secondary surgery with IS screws with and without C-clamp (Model 2 subgroup analysis)

\begin{tabular}{|c|c|c|}
\hline \multirow[b]{2}{*}{ Adjustment } & \multicolumn{2}{|c|}{ IS-screws sub-group ( $\mathrm{N}=243$ ) } \\
\hline & OR $(95 \% \mathrm{Cl})$ & p-value \\
\hline \multicolumn{3}{|l|}{ Crude } \\
\hline No C-clamp & ref & \\
\hline With C-clamp & $7.97(2.21-28.69)$ & $\leq 0.001$ \\
\hline \multicolumn{3}{|l|}{ Adjusted } \\
\hline No C-clamp & ref & 0.042 \\
\hline With C-clamp & $4.67(1.06-20.64)$ & \\
\hline \multicolumn{3}{|l|}{ Sex } \\
\hline Male & ref & 0.450 \\
\hline Female & $1.63(0.46-5.76)$ & \\
\hline Age (years) & $1.00(0.46-5.76)$ & 0.824 \\
\hline \multicolumn{3}{|l|}{ Laparotomy } \\
\hline No & ref & 0.053 \\
\hline Yes & $7.25(0.97-54.0)$ & \\
\hline
\end{tabular}

